Les Comités centraux seraient invités à présenter un rapport sur ce sujet soit au Comité international, soit à la prochaine Conférence et signaleraient quelles sont les mesures édictées à cet égard par les autorités militaires de leurs pays.

Dr Ferriere.

\title{
ALLEMAGNE
}

\section{Brancard roulant de fortune, traîné par deux bicyclettes.}

Nous avons mentionné, dans le dernier Bulletin ${ }^{1}$, l'intéressant brancard roulant sur bicyclettes du $D^{\mathbf{r}}$ Jules Nord, dont le Caducée ${ }^{2}$ a donné dans la suite une description détaillée avec figures.

Un des derniers numéros de la Deutsche Militärärztliche Zeitschrift ${ }^{3}$ décrit un agencement analogue, mais improvisé avec des pièces de bois mobiles, adaptées aux bicyclettes à peu près dans la même disposition que le cadre portebrancard du Dr Nord.

Ces agencements sont intéressants à signaler en ce qu'ils peuvent rendre des services réels en pays de plaines et sur de bonnes routes, non seulement en temps de guerre, mais aussi à l'occasion de toutes espèces d'accidents obligeant au transport rapide et commode d'un malade couché. Le brancard roulant improvisé sur bicyclettes du Stabsarzt $D^{r}$ Sachs-Müke semble, à cet égard, d'une construction ingénieuse et facile à réaliser en peu de temps.

$$
\text { Dr F. }
$$

${ }^{1}$ Voy. p. 44.

${ }^{2} \mathrm{~N}^{\mathrm{o}} 4,1912$, p. 50.

${ }^{3} N^{0} 4,1912$, p. 138, Stabsarzt Dr Sachs- Müke, Beuthen O. S. 